\title{
Pulmonary Function Changes Over 1 Year After Lobectomy in Lung Cancer
}

\author{
Hyun Koo Kim MD PhD, Yoo Jin Lee MSc, Kook Nam Han MD PhD, and \\ Young Ho Choi MD PhD
}

\begin{abstract}
BACKGROUND: This study was conducted to measure the serial changes in pulmonary function over 12 months after lobectomy in subjects with lung cancer and to evaluate the actual recovery of pulmonary function in comparison with the predicted postoperative values. METHODS: Subjects who underwent lobectomy for primary lung cancer were included in this study. In the statistical analysis, we included data from 76 subjects (52 men and 24 women; mean age, 63.4 y) who completed perfusion scintigraphy 1 week before surgery and $F E V_{1}$ and diffusion capacity of the lung for carbon monoxide $\left(\mathrm{D}_{\mathrm{LCO}}\right)$ assessments preoperatively and at 1,6 , and 12 months postoperatively. RESULTS: The actual percent-of-predicted $F E V_{1} 1$ month postoperatively was $77.9 \%$ of the preoperative value, which was almost equal to the predicted postoperative value, and significantly increased to $84.3 \%$ by 6 months and $84.2 \%$ at 12 months. The actual percent-of-predicted $D_{\text {LCO }} 1$ month postoperatively was $81.8 \%$ of the preoperative value, which was similar to the predicted postoperative value, and also significantly increased to $91.3 \%$ at 6 months and $96.5 \%$ at 12 months. However, the actual pulmonary function test results at $1 \mathrm{y}$ in subjects with COPD or in those who underwent thoracotomy or received adjuvant chemotherapy were not different from the predicted postoperative values. CONCLUSIONS: Actual pulmonary function compared with predicted postoperative values improved over time over 1 y after lobectomy. However, this improvement was not observed in subjects with COPD or in those who underwent thoracotomy or received postoperative adjuvant chemotherapy. Key words: pulmonary function; lobectomy; lung cancer. [Respir Care 2016;61(3):376-382. (C) 2016 Daedalus Enterprises]
\end{abstract}

\section{Introduction}

Lung cancer is one of the most common malignancies and is one of the leading causes of death worldwide. ${ }^{1}$ Surgical resection has been regarded as the best treatment for controlling stage I, stage II, and part of stage III $_{\mathrm{A}}$

\footnotetext{
Drs Kim, Han, and Choi are affiliated with the Departments of Thoracic and Cardiovascular Surgery, Korea University Guro Hospital, Korea University College of Medicine, Seoul, Korea. Ms Lee is affiliated with the Korea University College of Medicine, Seoul, Korea.
}

This research was supported by Ministry of Education, Science, and Technology Grant 20120003904; the National Research Foundation of Korea (NRF) grant, funded by the Korean government (MEST) (Grant 2012012166); and the Korean Health Technology R\&D Project, Ministry of Health and Welfare, Republic of Korea (Grant A121074). The authors have disclosed no conflicts of interest.

Dr Kim and Ms Lee contributed equally to this work. non-small-cell lung cancer. However, in some subjects with early stage non-small-cell lung cancer, poor respiratory function may interfere with surgery because of the increased risk for perioperative morbidity and mortality and the possibility of long-term postoperative disability secondary to respiratory insufficiency. ${ }^{2}$ Baser et $\mathrm{al}^{3}$ reported that $37 \%$ of subjects who had anatomically resectable lung cancers were excluded from surgical resection only because of poor lung function. Therefore, predicting postoperative pulmonary function, particularly $\mathrm{FEV}_{1}$ and the diffusion capacity of the lung for carbon monoxide

\footnotetext{
Correspondence: Hyun Koo Kim MD PhD, Departments of Thoracic and Cardiovascular Surgery, Korea University Guro Hospital, Korea University College of Medicine, 97 Guro-donggil, Guro-gu, Seoul 152-703, Korea. E-mail: kimhyunkoo@korea.ac.kr.
}

DOI: $10.4187 /$ respcare. 04284 
$\left(\mathrm{D}_{\mathrm{LCO}}\right)$, plays an important role in determining candidates for surgical resection and the extent of resection. ${ }^{4}$

A number of related studies have been conducted to predict pulmonary function after surgery. ${ }^{5}$ However, reaching a definitive conclusion about predicting postoperative pulmonary function was difficult in most of these studies because they were based on small samples and short monitoring periods ( 3 or 6 months at the longest). ${ }^{6-8}$ Furthermore, surgical techniques and postoperative care have steadily improved since these studies were performed.

Recently, the authors showed that actual pulmonary function results at approximately 1 month after surgery were similar to predicted postoperative pulmonary function values. ${ }^{9}$ In addition, Brunelli et $\mathrm{al}^{10}$ performed a prospective study of a large sample ( $>200$ subjects) and found that actual postoperative lung function reached predicted postoperative values at 1 month after surgery and showed further improvement at 3 months after surgery. Based on these studies, we aimed to evaluate whether pulmonary function would continue to improve during the long-term follow-up after operation, and in the present study, we monitored the changes in actual postoperative lung function over $1 \mathrm{y}$ after lobectomy in subjects with lung cancer and evaluated the degree of actual recovery compared with predicted postoperative values. In addition, we analyzed differences in the results according to factors including the presence or absence of COPD, surgical method (video-assisted thoracoscopic surgery [VATS] vs thoracotomy), and the use of adjuvant chemotherapy after operation.

\section{Methods}

Subjects who underwent lobectomy for primary lung cancer from April 2009 through January 2012 at Korea University Guro Hospital were included in this study. Subject data were prospectively collected and were analyzed. Exclusionary criteria included cancer with chest wall invasion, endobronchial cancer with post-obstructive pneumonitis, and subjects who underwent neoadjuvant chemotherapy. Patients who had any major complications or required ventilatory support that interfered with assessment of pulmonary function in the postoperative period were also excluded. This study was approved by the Ethics Committee of Korea University Guro Hospital (KUGH 2014-01-0004), and written informed consent was obtained from all subjects, in accordance with the Declaration of Helsinki.

Subjects underwent pulmonary function tests and perfusion scintigraphy within 1 week before surgery and postoperative pulmonary function tests at 1,6 , and 12 months after surgery. The pulmonary function tests were performed according to the published guidelines using a spirometer (Vmax22, SensorMedics, Yorba Linda, California). ${ }^{11}$ The

\section{QUICK LOOK}

\section{Current knowledge}

Lung cancer is one of the most common malignancies and a leading cause of death worldwide. Surgical resection is the standard of care in non-small-cell lung cancer. Poor respiratory function may preclude surgery in select patients due to the increased risk for perioperative morbidity and mortality. Long-term postoperative disability secondary to respiratory failure represents a significant cost burden.

\section{What this paper contributes to our knowledge}

Actual pulmonary function compared with predicted postoperative values improved $1 \mathrm{y}$ after lobectomy. This improvement was not observed in subjects with COPD, in those who underwent thoracotomy, or those who received postoperative adjuvant chemotherapy.

$\mathrm{D}_{\mathrm{LCO}}$ was measured using the single-breath method. Spirometry and $\mathrm{D}_{\mathrm{LCO}}$ results were collected after bronchodilator administration and are expressed as percentages of age, sex, and height of the subject according to the European Community for Steel and Coal prediction equations. ${ }^{12}$

The preoperative radionuclide quantitative lung perfusion scans were performed in all subjects with an Infinia multidetector system (GE Medical Systems, Haifa, Israel) to estimate the predicted postoperative values, as described by $\mathrm{Ali},{ }^{13}$, which was our routine procedure until January 2009: (1) postoperative percent-of-predicted $\mathrm{FEV}_{1}=$ preoperative percent-of-predicted $\mathrm{FEV}_{1} \times(100 \%$ - projected percentage loss of lung function) and (2) postoperative percent-of-predicted $\mathrm{D}_{\mathrm{LCO}}=$ preoperative percent-of-predicted $\mathrm{D}_{\mathrm{LCO}} \times(100 \%$ - projected percentage loss of lung function).

\section{Statistics}

The descriptive statistics of $\mathrm{FEV}_{1}$ and $\mathrm{D}_{\mathrm{LCO}}$ measurements are presented as the mean and SD. We used paired and independent $t$ tests to compare groups with normally distributed data and the Wilcoxon signed-rank test and Mann-Whitney test for non-normal data. Data analysis was performed with SPSS 20 (SPSS, Chicago, Illinois).

\section{Results}

A total of 76 subjects (52 men and 24 women) who completed $\mathrm{FEV}_{1}$ and $\mathrm{D}_{\mathrm{LCO}}$ assessments preoperatively and at 1,6 , and 12 months postoperatively were included in the statistical analysis. 
The characteristics of these subjects are shown in Table 1. The mean age of the subjects was $63.4 \pm 8.98$ y (range, 43-80 y). The average $\mathrm{FEV}_{1} / \mathrm{FVC}$ ratio was $0.72 \pm 0.10$. Seven subjects $(9.2 \%)$ had COPD, $46(60.5 \%)$ underwent resection via VATS, and 22 (29\%) received adjuvant chemotherapy after surgery. The pathology was adenocarcinoma in 38 subjects (50\%), squamous cell carcinoma in 30 subjects $(39.5 \%)$, and other in 8 subjects $(10.5 \%)$. At clinical staging, all subjects appeared node-negative; the pathologic stages were N0 in 62 subjects, N1 in 7, and N2 in 7.

Preoperative and predicted and actual postoperative values at each time point in subjects with complete follow-up data are shown in Table 2 and Figure 1. At 1, 6, and 12 months after operation, actual percent-of-predicted $\mathrm{FEV}_{1}$ values were $77.9,84.3$, and $84.2 \%$, respectively, of the preoperative values. The actual percent-of-predicted $\mathrm{FEV}_{1}$ was almost equal to the predicted postoperative value at 1 month and increased at 6 months $(P=.03)$ but showed no further increase at 12 months. Actual postoperative percent-of-predicted $\mathrm{D}_{\mathrm{LCO}}$ values were $81.8,91.3$, and $96.5 \%$ of the preoperative values at 1,6 , and 12 months, respectively. The actual percent-of-predicted $\mathrm{D}_{\mathrm{LCO}}$ was similar to the predicted postoperative value at 1 month and increased at 6 months $(P=.01)$. Compared with the percent-of-predicted $\mathrm{FEV}_{1}$, the actual percent-of-predicted

Table 1. Subject Characteristics

\begin{tabular}{lc}
\hline \hline \multicolumn{1}{c}{ Variables } & Values \\
\hline Male/female, $n$ & $52 / 24$ \\
Age, mean \pm SD y & $63.4 \pm 8.98$ \\
FEV $_{1} / \mathrm{FVC}$, mean $\pm \mathrm{SD}$ & $0.72 \pm 0.10$ \\
Pathology, $n(\%)$ & \\
$\quad$ Adenocarcinoma & $38(50.0 \%)$ \\
Squamous cell carcinoma & $30(39.5 \%)$ \\
Other & $8(10.5 \%)$ \\
Presence of COPD, $n(\%)$ & $7(9.2 \%)$ \\
Type of surgery, $n(\%)$ & \\
VATS & $46(60.5 \%)$ \\
$\quad$ Thoracotomy & $30(39.5 \%)$ \\
Adjuvant chemotherapy, $n(\%)$ & $22(29.0 \%)$ \\
& \\
\hline VATS = video-assisted thoracoscopic surgery & \\
\hline
\end{tabular}

$\mathrm{D}_{\mathrm{LCO}}$ showed a greater increase and approximated the preoperative value at $1 \mathrm{y}$ after operation.

Figure 2 shows the comparative pulmonary function data according to the presence (7 subjects) or absence (69 subjects) of COPD. Significant improvements were observed in percent-of-predicted $\operatorname{FEV}_{1}(P=.02)$ and percent-of-predicted $\mathrm{D}_{\mathrm{LCO}}(P<.01)$ between 1 and 6 months after operation in non-COPD subjects. However, no significant recovery of pulmonary function was observed over the entire period in those with COPD. Significant differences in preoperative and predicted postoperative percentof-predicted $\mathrm{FEV}_{1}$ values between the 2 groups did not reduce during the 1-y follow-up after operation. On the other hand, from 6 months after operation, the actual percent-of-predicted $\mathrm{D}_{\mathrm{LCO}}$ showed a dramatic improvement in non-COPD subjects compared with those with COPD.

Figure 3 shows comparative pulmonary function data according to the type of surgery (VATS in 46 subjects vs thoracotomy in 30). Significant improvements were observed in percent-of-predicted $\mathrm{FEV}_{1}(P=.02)$ and percent-of-predicted $\mathrm{D}_{\mathrm{LCO}}(P=.01)$ between 1 and 6 months after operation in subjects who underwent VATS. However, no significant improvement was observed over the

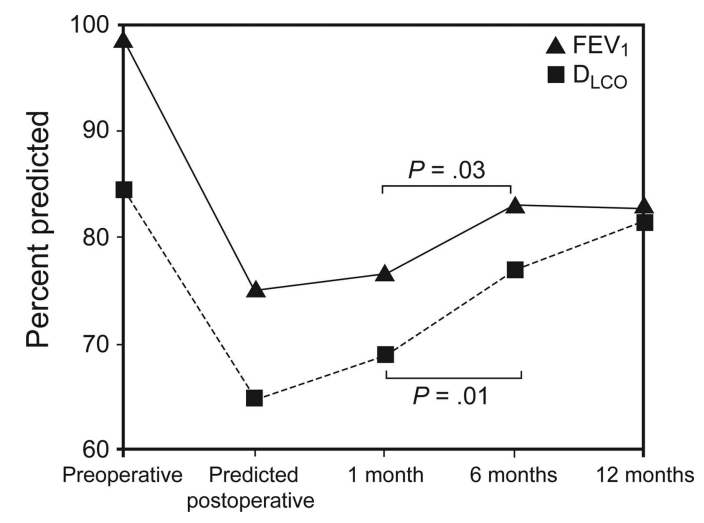

Fig. 1. Time-series graphs showing the actual postoperative percent-of-predicted $\mathrm{FEV}_{1}$ and percent-of-predicted diffusion capacity of the lung for carbon monoxide $\left(D_{\text {LCO }}\right)$ values at each postoperative time point relative to the preoperative and predicted postoperative values. The actual percent-of-predicted $\mathrm{FEV}_{1}$ $(P=.03)$ and percent-of-predicted $\mathrm{D}_{\mathrm{LCO}}(P=.01)$ values significantly increased between 1 and 6 months postoperatively.

Table 2. Preoperative, Predicted Postoperative, and Actual FEV ${ }_{1}$ and $\mathrm{D}_{\mathrm{LCO}}$ Values

\begin{tabular}{lccccc}
\hline \hline \multicolumn{1}{c}{ Variables } & Preoperative & $\begin{array}{c}\text { Predicted } \\
\text { Postoperative }\end{array}$ & $\begin{array}{c}\text { Actual 1-Month } \\
\text { Postoperative }\end{array}$ & $\begin{array}{c}\text { Actual 6-Month } \\
\text { Postoperative }\end{array}$ & $\begin{array}{c}\text { Actual 12-Month } \\
\text { Postoperative }\end{array}$ \\
\hline $\mathrm{FEV}_{1}, \mathrm{~L}$ & $2.30 \pm 0.56$ & $1.80 \pm 0.48(76.1)$ & $1.80 \pm 0.48(77.4)$ & $2.00 \pm 0.52(83.3)$ & $2.00 \pm 0.51(84.6)$ \\
$\mathrm{FEV}_{1}, \%$ predicted & $98.50 \pm 17.76$ & $74.98 \pm 14.53(76.0)$ & $76.70 \pm 16.46(77.9)$ & $83.00 \pm 20.18(84.3)$ & $82.90 \pm 18.80(84.2)$ \\
$\mathrm{D}_{\mathrm{LCO}}, \mathrm{mL} / \mathrm{min} / \mathrm{mm} \mathrm{Hg}$ & $14.20 \pm 4.30$ & $10.90 \pm 3.34(76.8)$ & $11.50 \pm 3.12(80.8)$ & $12.80 \pm 4.48(90.0)$ & $13.60 \pm 4.35(95.6)$ \\
$\mathrm{D}_{\mathrm{LCO}}, \%$ & $84.40 \pm 9.72$ & $64.80 \pm 14.04(76.7)$ & $69.00 \pm 16.13(81.8)$ & $77.00 \pm 21.98(91.3)$ & $81.40 \pm 20.14(96.5)$
\end{tabular}

Data are expressed as mean \pm SD (\% of preoperative value)

$\mathrm{D}_{\mathrm{LCO}}=$ diffusion capacity of the lung for carbon monoxide 

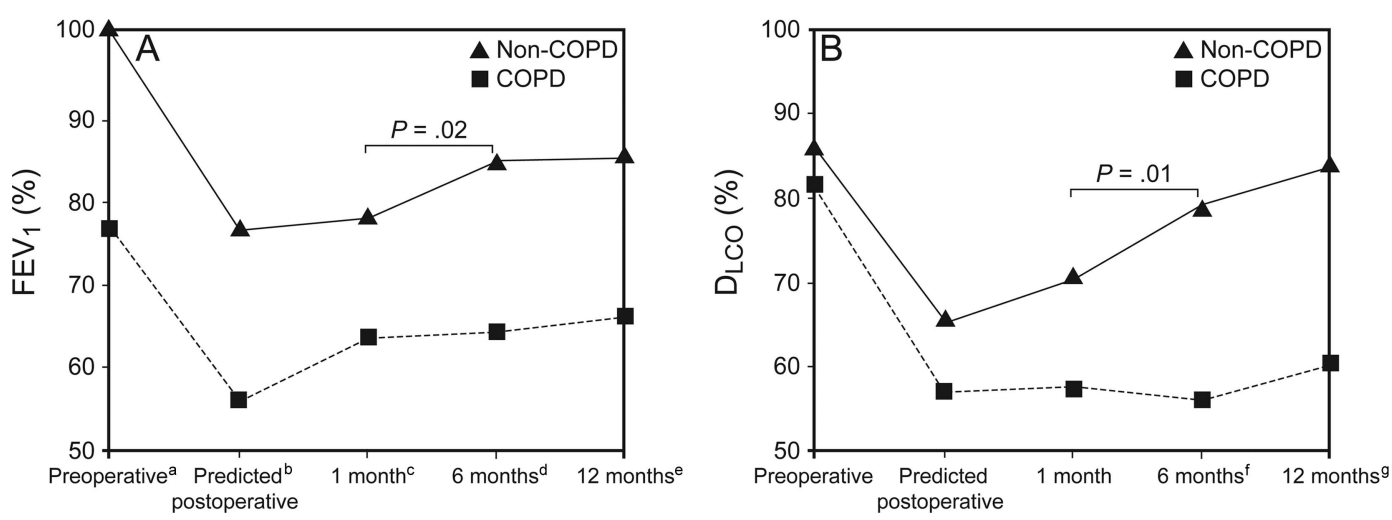

Fig. 2. A: Time-series graphs showing the actual postoperative percent-of-predicted $\mathrm{FEV}_{1}$ values at each postoperative time point relative to the preoperative and predicted postoperative percent-of-predicted FEV 1 values in subjects with and without COPD. The actual percentof-predicted $\mathrm{FEV}_{1}$ values significantly increased between 1 and 6 months postoperatively only in subjects without COPD $(P=.02)$. The preoperative, predicted postoperative, and actual postoperative percent-of-predicted $\mathrm{FEV}_{1}$ values at all time points were significantly higher in subjects without COPD than in the COPD group (a, $P=.02 ; \mathrm{b}, P=.02 ; \mathrm{c}, P=.02 ; \mathrm{d}, P=.01$; e, $P=.01)$. B: Time-series graphs showing the actual percent-of-predicted diffusion capacity of the lung for carbon monoxide $\left(D_{\text {Lco }}\right)$ values at each postoperative time point relative to the preoperative and predicted postoperative percent-of-predicted $D_{\text {Lco }}$ values in subjects with and without COPD. The actual percent-of-predicted $\mathrm{D}_{\mathrm{LCO}}$ values significantly increased between 1 and 6 months postoperatively only in subjects without COPD $(P<.01)$. The actual postoperative percent-of-predicted $D_{\text {LCO }}$ values at 6 and 12 months were significantly higher in subjects without COPD than in those with COPD (f, $P<.001 ; \mathrm{g}, P<.001)$.
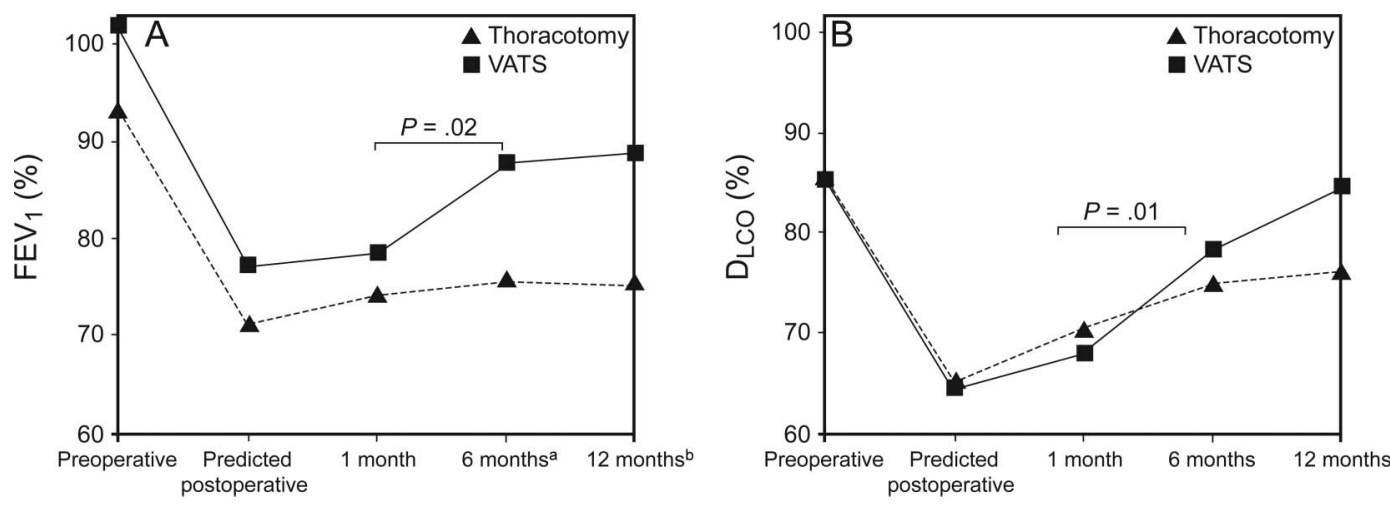

Fig. 3. A: Time-series graphs showing the actual percent-of-predicted $F_{E V}$ values at each postoperative time point relative to the preoperative and predicted postoperative percent-of-predicted $\mathrm{FEV}_{1}$ values in subjects who underwent video-assisted thoracoscopic

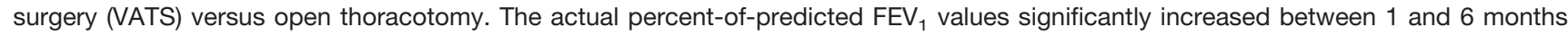

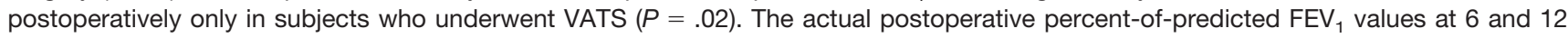
months were significantly higher in those who underwent VATS compared with the thoracotomy group $(\mathrm{a}, P<.01 ; \mathrm{b}, P<.01)$. B: Time-series graphs showing the actual postoperative percent-of-predicted diffusion capacity of the lung for carbon monoxide $\left(D_{L c 0}\right)$ values at each time point relative to the preoperative and predicted postoperative percent-of-predicted $D_{\text {Lco }}$ values in subjects who underwent VATS versus open thoracotomy. The actual percent-of-predicted $D_{\text {Lco }}$ values significantly increased between 1 and 6 months postoperatively only in subjects who underwent VATS $(P=.01)$, but overall, the percent-of-predicted $D_{\text {Lco }}$ values were not significantly different between the 2 groups.

entire period in the thoracotomy group. From 6 months after operation, the actual percent-of-predicted $\mathrm{FEV}_{1}$ showed significant improvement after VATS versus thoracotomy, although the actual percent-of-predicted $\mathrm{D}_{\mathrm{LCO}}$ showed no difference between the 2 groups during the $1-y$ follow-up after operation.

Figure 4 shows the comparative pulmonary function data between subjects receiving adjuvant chemotherapy (22 subjects) or not (54 subjects). Significant improvements were observed in percent-of-predicted $\mathrm{FEV}_{1}$
$(P=.02)$ and percent-of-predicted $\mathrm{D}_{\mathrm{LCO}}(P=.02)$ between 1 and 6 months after operation in the nonadjuvant group. However, no significant improvement was observed over the entire period in the adjuvant group. From 6 months after operation, the actual percent-of-predicted $\mathrm{FEV}_{1}$ showed significant improvement in the non-adjuvant group compared with the adjuvant group, and the actual percent-of-predicted $\mathrm{D}_{\mathrm{LCO}}$ showed significant improvement in the non-adjuvant group compared with the adjuvant group at $1 \mathrm{y}$ after operation. 

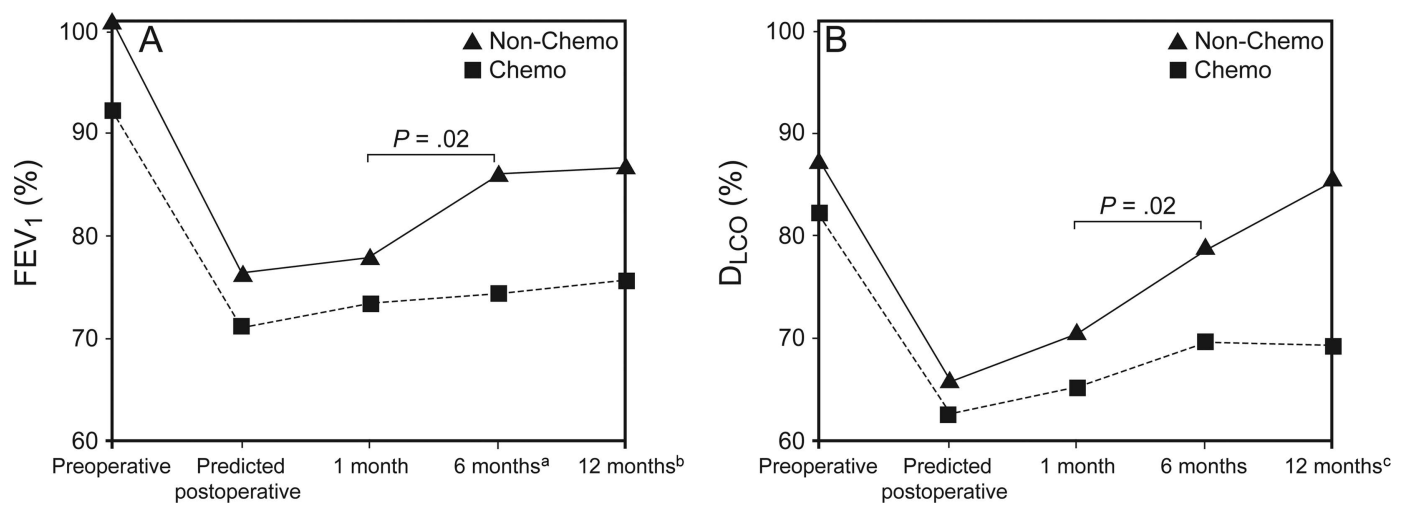

Fig. 4. A: Time-series graphs showing the actual postoperative percent-of-predicted $F_{E V}$ values at each time point relative to the preoperative and predicted postoperative percent-of-predicted $\mathrm{FEV}_{1}$ values in subjects who underwent adjuvant chemotherapy versus those who did not. The actual percent-of-predicted $\mathrm{FEV}_{1}$ increased significantly between 1 and 6 months postoperatively only in the

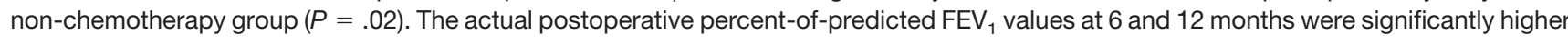
in the non-chemotherapy group than in the chemotherapy group $(\mathrm{a}, P=.02 ; \mathrm{b}, P=.02)$. B: time-series graphs showing the actual postoperative percent-of-predicted diffusion capacity of the lung for carbon monoxide $\left(D_{\text {Lco }}\right)$ values at each time point relative to the preoperative and predicted postoperative percent-of-predicted $D_{\text {Lco }}$ values in subjects receiving and not receiving chemotherapy. The actual percent-of-predicted $D_{\text {Lco }}$ values significantly increased between 1 and 6 months postoperatively only in the non-chemotherapy group $(P=.02)$. The actual postoperative percent-of-predicted $D_{\text {Lco }}$ value at 12 months was significantly higher in the non-chemotherapy group versus the chemotherapy group (c, $P<.01)$.

\section{Discussion}

Predicted postoperative pulmonary function in patients undergoing major pulmonary resection for lung cancer plays an important role in determining operability and predicting quality of life after surgery. In particular, $\mathrm{FEV}_{1}$ and $\mathrm{D}_{\mathrm{LCO}}$ are useful predictors of postoperative mortality and complications. ${ }^{14,15}$ In a previous study, ${ }^{9}$ we showed that predicted postoperative pulmonary function was similar to the actual postoperative value at 1 month after surgery, and Brunelli et al ${ }^{10}$ demonstrated that actual postoperative lung function improved to an even greater extent at 3 months after surgery. Based on these findings, we wanted to know how much and for how long pulmonary function would continue to be recovered after major pulmonary resection in lung cancer patients.

In the present study, we found that actual percent-ofpredicted $\mathrm{FEV}_{1}$ was similar to the predicted value at 1 month after surgery, significantly increased to 1.11 times the predicted postoperative value at 6 months after surgery, and remained at approximately the same level $(84.0 \%$ of the preoperative value) until 12 months after surgery. The actual percent-of-predicted $\mathrm{D}_{\mathrm{LCO}}$ was not different from the predicted value at 1 month after surgery but significantly increased to 1.19 times the predicted postoperative value at 6 months and eventually reached 1.26 times the predicted postoperative value by 12 months (97.2\% of the preoperative value). These results indicate that the postoperative percent-of-predicted $\mathrm{D}_{\mathrm{LCO}}$ exhibits greater recovery compared with $\mathrm{FEV}_{1}$, which is similar to the findings reported by Brunelli et al. ${ }^{10}$ This finding may be explained by pulmonary vascular and hemodynamic compensatory mechanisms. ${ }^{16}$

Several authors have reported that the percent-of-predicted $\mathrm{FEV}_{1}$ in COPD subjects was decreased to a lesser extent or even improved after surgical resection compared with the percent-of-predicted $\mathrm{FEV}_{1}$ in non-COPD subjects, ${ }^{17-19}$ and the difference was more prominent at the early phase (1-3 months) after surgery. ${ }^{10,20}$ This might be attributed to the similar effect of lung volume reduction surgery for subjects with bullous emphysema. Further, it has also been noted that the actual postoperative percentof-predicted $\mathrm{D}_{\mathrm{LCO}}$ in subjects with COPD shows a marked increase with improvement of the ventilation/perfusion ratio. ${ }^{17-19}$ In the present study, the actual percent-of-predicted $\mathrm{FEV}_{1}$ had a tendency to exceed the predicted postoperative value in subjects with COPD (1.13 times the predicted postoperative value) at 1 month after surgery $(P=.06)$, but these values did not increase thereafter; meanwhile, the actual percent-of-predicted $\mathrm{D}_{\mathrm{LCO}}$ in COPD subjects showed no improvement, reaching only $73.5 \%$ of the preoperative value (1.05 times the predicted postoperative value) at $1 \mathrm{y}$ after surgery. This inconsistency with the previous results may be due to the small number of COPD subjects $(n=7)$ in our study. On the other hand, the actual percent-of-predicted $\mathrm{FEV}_{1}$ in the non-COPD group was similar to the predicted postoperative value (1.01 times the predicted postoperative value) at 1 month after surgery, significantly increased to 1.11 times the predicted postoperative value at 6 months, and remained at approximately the same level at 12 months $(85.1 \%$ of the preoperative value). The actual percent-of-predicted $\mathrm{D}_{\mathrm{LCO}}$ 
also showed continuous improvement in non-COPD subjects after surgery and reached $97 \%$ of the preoperative value (1.27 times the predicted postoperative value).

VATS is associated with faster recovery of pulmonary function after surgery because of its reduced invasiveness, which reduces postoperative pain, impairment of respiratory muscles, and damage to the thoracic wall. ${ }^{21-25}$ In the present study, the recovery of actual pulmonary function after VATS was not different from that after thoracotomy at 1 month after operation. However, the actual percentof-predicted $\mathrm{FEV}_{1}$ in the VATS group significantly increased at 6 months after operation to 1.14 times the predicted postoperative value and eventually reached $89.0 \%$ of the preoperative value at 12 months (1.20 times the predicted postoperative value), whereas it did not increase significantly in the thoracotomy group. Although there were no significant differences overall in the percent-ofpredicted $\mathrm{D}_{\mathrm{LCO}}$ values between the 2 groups, the actual percent-of-predicted $\mathrm{D}_{\mathrm{LCO}}$ in the VATS group had recovered significantly to $91.8 \%$ of the preoperative value (1.22 times the predicted postoperative value) at 6 months and continued to increase to $99.2 \%$ of the preoperative value (1.32 times the predicted postoperative value) at 12 months, whereas there was no significant improvement of the actual percent-of-predicted $\mathrm{D}_{\mathrm{LCO}}$ observed in the thoracotomy subjects $(82.2 \%$ of the preoperative value at 1 month to $89.1 \%$ at 12 months).

Adjuvant chemotherapeutic agents for non-small-cell lung cancer are known to have various adverse effects, including dyspnea, cough, wheezing, chest tightness, and hypersensitivity reaction. ${ }^{14,26,27}$ Approximately 10\% of subjects who receive chemotherapy exhibit pulmonary toxicity, which mainly manifests as a parenchymal lung injury, such as pneumonitis or interstitial lung disease. ${ }^{14,15,26,28,29}$ This toxicity might present as airway or pleural disease or in various other ways. ${ }^{15,29}$ Therefore, adjuvant chemotherapy after major lung resection can affect the recovery of pulmonary function. In the present study, the actual percent-of-predicted $\mathrm{FEV}_{1}$ significantly increased to $85.9 \%$ of the preoperative value (1.11 times the predicted postoperative value) at 12 months in subjects who did not receive adjuvant chemotherapy, whereas the increase was not significant in the adjuvant group (79.0\% of the preoperative value at 1 month to $81.9 \%$ at 12 months). The actual percent-of-predicted $\mathrm{D}_{\mathrm{LCO}}$ in the non-adjuvant group showed a marked recovery to $98.4 \%$ of the preoperative value (1.29 times the predicted postoperative value) at 12 months, whereas no significant improvement of the actual percent-of-predicted $\mathrm{D}_{\mathrm{LCO}}$ was observed in the adjuvant group (79.6\% at 1 month to $83.9 \%$ at 12 months). This result demonstrates the negative effect of adjuvant chemotherapy on pulmonary function recovery after operation and is compatible with the findings of previous studies. This study had limitations, including the small number of subjects and the uneven distribution for subgroup analysis, especially for the presence of COPD.

\section{Conclusions}

In conclusion, the actual pulmonary function after surgery improved above the level of the predicted postoperative values for $1 \mathrm{y}$. The postoperative predicted values are an underestimate of the actual lung function recovery over a period of $1 \mathrm{y}$. This has clinical implications because this underestimation may lead to curative resection being withheld in marginal candidates. Therefore, the systematic use of exercise testing should be considered. ${ }^{16}$ However, this improvement was not observed in subjects with COPD, subjects who underwent thoracotomy, or those who received postoperative adjuvant chemotherapy. The result of this study should be useful for the determination of surgical candidates, of the extent of resection, and of the strategy of postoperative pulmonary care.

\section{REFERENCES}

1. Pisani P, Bray F, Parkin DM. Estimates of the world-wide prevalence of cancer for 25 sites in the adult population. Int $\mathrm{J}$ Cancer 2002;97(1):72-81.

2. Chae EJ, Kim N, Seo JB, Park JY, Song JW, Lee HJ, et al. Prediction of postoperative lung function in patients undergoing lung resection: dual-energy perfusion computed tomography versus perfusion scintigraphy. Investigative radiology 2013;48(8):622-627.

3. Baser S, Shannon VR, Eapen GA, Jimenez CA, Onn A, Keus L, et al. Pulmonary dysfunction as a major cause of inoperability among patients with non-small-cell lung cancer. Clin Lung Cancer 2006; 7(5):344-349.

4. Beckles MA, Spiro SG, Colice GL, Rudd RM, American College of Chest Physicians. The physiologic evaluation of patients with lung cancer being considered for resectional surgery. Chest 2003;123(1 Suppl):105S-114S.

5. Zeiher BG, Gross TJ, Kern JA, Lanza LA, Peterson MW. Predicting postoperative pulmonary function in patients undergoing lung resection. Chest 1995;108(1):68-72.

6. Pierce RJ, Copland JM, Sharpe K, Barter CE. Preoperative risk evaluation for lung cancer resection: predicted postoperative product as a predictor of surgical mortality. Am J Respir Crit Care Med 1994;150(4):947-955.

7. Corris PA, Ellis DA, Hawkins T, Gibson GJ. Use of radionuclide scanning in the preoperative estimation of pulmonary function after pneumonectomy. Thorax 1987;42(4):285-291.

8. Ladurie ML, Ranson-Bitker B. Uncertainties in the expected value for forced expiratory volume in one second after surgery. Chest 1986;90(2):222-228.

9. Kim HK, Yoo D, Sung HK, Lee HJ, Choi YH. Vibration response imaging in prediction of pulmonary function after pulmonary resection. Ann Thorac Surg 2012;94(5):1680-1686.

10. Brunelli A, Refai M, Salati M, Xiumé F, Sabbatini A. Predicted versus observed FEV1 and DLCO after major lung resection: a prospective evaluation at different postoperative periods. Ann Thorac Surg 2007;83(3):1134-1139.

11. Miller MR, Hankinson J, Brusasco V, Burgos F, Casaburi R, Coates A, et al. Standardisation of spirometry. Eur Respir J 2005;26(2):319-338.

12. Waalkens HJ, Merkus PJ, van Essen-Zandvliet EE, Brand PL, Gerritsen J, Duiverman EJ, et al. Assessment of bronchodilator response 


\section{Pulmonary Function After Lobectomy}

in children with asthma: Dutch CNSLD Study Group. Eur Respir J 1993;6(5):645-651.

13. Ali MK, Ewer MS, Atallah MR, Mountain CF, Dixon CL, Johnston DA, Haynie TP. Regional and overall pulmonary function changes in lung cancer. Correlations with tumor stage, extent of pulmonary resection, and patient survival. J Thorac Cardiovasc Surg 1983;86(1):1-8.

14. Limper $\mathrm{AH}$. Chemotherapy-induced lung disease: clinics in chest medicine 2004;25(1):53-64.

15. Ryu JH. Chemotherapy-induced pulmonary toxicity in lung cancer patients. J Thorac Oncol 2010;5(9):1313-1314.

16. Brunelli A, Xiumé F, Refai M, Salati M, Marasco R, Sciarra V, Sabbatini A. Evaluation of expiratory volume, diffusion capacity, and exercise tolerance following major lung resection: a prospective follow-up analysis. Chest 2007;131(1):141-147.

17. Sekine Y, Iwata T, Chiyo M, Yasufuku K, Motohashi S, Yoshida S, et al. Minimal alteration of pulmonary function after lobectomy in lung cancer patients with chronic obstructive pulmonary disease. Ann Thorac Surg 2003;76(2):356-361; discussion 362.

18. Baldi S, Ruffini E, Harari S, Roviaro GC, Nosotti M, Bellaviti N, et al. Does lobectomy for lung cancer in patients with chronic obstructive pulmonary disease affect lung function? a multicenter national study. J Thorac Cardiovasc Surg 2005;130(6):1616-1622.

19. Edwards JG, Duthie DJ, Waller DA. Lobar volume reduction surgery: a method of increasing the lung cancer resection rate in patients with emphysema. Thorax 2001;56(10):791-795.

20. Seok Y, Jheon S, Cho S. Serial changes in pulmonary function after video-assisted thoracic surgery lobectomy in lung cancer patients. Thorac Cardiovasc Surg 2014;62(2):133-139.
21. Flores RM, Park BJ, Dycoco J, Aronova A, Hirth Y, Rizk NP, et al. Lobectomy by video-assisted thoracic surgery (VATS) versus thoracotomy for lung cancer. J Thorac Cardiovasc Surg 2009;138(1): 11-18.

22. Nakata M, Saeki H, Yokoyama N, Kurita A, Takiyama W, Takashima S. Pulmonary function after lobectomy: video-assisted thoracic surgery versus thoracotomy. Ann Thorac Surg 2000;70(3):938-941.

23. Kaseda S, Aoki T, Hangai N, Shimizu K. Better pulmonary function and prognosis with video-assisted thoracic surgery than with thoracotomy. Ann Thorac Surg 2000;70(5):1644-1646.

24. Nagahiro I, Andou A, Aoe M, Sano Y, Date H, Shimizu N. Pulmonary function, postoperative pain, and serum cytokine level after lobectomy: a comparison of VATS and conventional procedure. Ann Thorac Surg 2001;72(2):362-365.

25. Handy JR, Asaph JW, Douville EC, Ott GY, Grunkemeier GL, Wu Y. Does video-assisted thoracoscopic lobectomy for lung cancer provide improved functional outcomes compared with open lobectomy? Eur J Cardiothorac Surg 2010;37(2):451-455.

26. Liu V, White DA, Zakowski MF, Travis W, Kris MG, Ginsberg MS, et al. Pulmonary toxicity associated with erlotinib. Chest 2007;132(3): 1042-1044.

27. Dimopoulou I, Galani H, Dafni U, Samakovii A, Roussos C, Dimopoulos MA. A prospective study of pulmonary function in patients treated with paclitaxel and carboplatin. Cancer 2002;94(2):452-458.

28. Vahid B, Marik PE. Pulmonary complications of novel antineoplastic agents for solid tumors. Chest 2008;133(2):528-538.

29. Limper A, Rosenow EC III. Drug-induced pulmonary disease. In Murray JF, Nadel J, editors. Textbook of Respiratory Medicine. Philadelphia: W.B. Saunders; 2000:1971-1984. 